\title{
Article
}

\section{Ethical supply chains: analysis, practices and performance measures}

Yusuf, Yahaya, Hawkins, Anya, Musa, Ahmed, Berishy, Nagham El, Schulze, Marion and Abubakar, Tijjani

Available at http://clok.uclan.ac.uk/10945/

Yusuf, Yahaya ORCID: 0000-0001-6045-3245, Hawkins, Anya, Musa, Ahmed, Berishy, Nagham El, Schulze, Marion and Abubakar, Tijjani (2014) Ethical supply chains: analysis, practices and performance measures. International Journal of Logistics Systems and Management, 17 (4). pp. 472-497. ISSN $1742-7967$

It is advisable to refer to the publisher's version if you intend to cite from the work. http://dx.doi.org/10.1504/IJLSM.2014.061016

For more information about UCLan's research in this area go to http://www.uclan.ac.uk/researchgroups/ and search for < name of research Group>.

For information about Research generally at UCLan please go to http://www.uclan.ac.uk/research/

All outputs in CLoK are protected by Intellectual Property Rights law, including Copyright law. Copyright, IPR and Moral Rights for the works on this site are retained by the individual authors and/or other copyright owners. Terms and conditions for use of this material are defined in the policies page.

\section{CLoK}

Central Lancashire online Knowledge www.clok.uclan.ac.uk

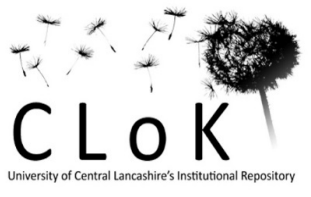




\title{
Ethical supply chains: analysis, practices and performance measures
}

\author{
Yahaya Yusuf*, Anya Hawkins and \\ Ahmed Musa
}

Lancashire Business School, University of Central Lancashire, Preston PR1 2HE, UK

E-mail: yyusuf@uclan.ac.uk

E-mail: anyahawkins1@gmail.com

E-mail: amusa@uclan.ac.uk

*Corresponding author

\section{Nagham El-Berishy}

Production Engineering, University of Bremen, 28359 Bremen, Germany

E-mail: elb@biba.uni-bremen.de

\section{Marion Schulze and Tijjani Abubakar}

Lancashire Business School,

University of Central Lancashire,

Preston PR1 2HE, UK

E-mail: mschulze@uclan.ac.uk

E-mail: tabubakar@uclan.ac.uk

\begin{abstract}
Ethics has been studied in numerous disciplines and its application to various practices has been investigated over the years such as in medicine and law. This has been relatively recently extended into the business arena, and has become a matter of growing interest for many companies. It has led to questions concerning what constitutes ethical behaviour, to what extent ethical practices should be adopted and what benefits a company may derive from its adoption. There are numerous processes involved in the transformation of a product from source to consumer, and these must be managed to produce an optimal balance of business requirements, specifically profitability, and a consideration of the wider impacts they may have or make. The supply chain has become vital to organisational success that companies now compete as supply chains rather than as individual entities. Therefore the ethical conduct of the supply chains has also begun to be scrutinised, both from an internal business performance perspective, and from the increasing concerns held by the numerous stakeholders of the organisation. In light of these developments, this paper explores the notion of ethics as it applies to supply chains. It also examines supply chain ethical practices and demonstrates that there is an empirical relationship between ethical practices and performance. The results show that ethical practices have positive impacts on the performance of the supply chain.
\end{abstract}


Keywords: ethics; supply chains; operations; analysis; performance measures.

Reference to this paper should be made as follows: Yusuf, Y., Hawkins, A., Musa, A., El-Berishy, N., Schulze, M. and Abubakar, T. (2014) 'Ethical supply chains: analysis, practices and performance measures’, Int. J. Logistics Systems and Management, Vol. 17, No. 4, pp.472-497.

Biographical notes: Yahaya Yusuf is a Professor of Logistics and Operations Management, Lancashire Business School, University of Central Lancashire. He was previously a Senior Lecturer at the University of Hull Business School and Lecturer, School of Engineering and Computer Science, University of Exeter. His research interests include agile manufacturing, supply chain management, supply chain technologies and enterprise resource planning. $\mathrm{He}$ has published articles in International Journal of Operations and Production Management (IJOPM), International Journal of Production Economics (IJPE), Journal of Intelligent Manufacturing, International Journal of Manufacturing Technology Management (IJMTM), Leadership and Organisation Development Journal and European Journal of Operational Research. He is on the editorial board of the journal, Benchmarking: An International Journal, and the International Journal of Modelling, Identification and Control as well as the International Journal of Logistics Systems and Management.

Anya Hawkins completed both her undergraduate and postgraduate degrees at the Lancashire Business School of the University of Central Lancashire. Her primary research interests are ethical business, ethical supply chain practices, and corporate social responsibility. She is also interested in enterprise systems.

Ahmed Musa is a Research Fellow in Lancashire Business School, University of Central Lancashire, Preston, Lancashire, UK. He was formerly with the Faculty of Engineering, Ahmadu Bello University, Zaria, Nigeria and Federal University of Technology, Minna, Nigeria. He received his $\mathrm{PhD}$ in Geomatics/Gravitational Physics from the University of Newcastle upon Tyne, UK. In the University of Central Lancashire, he teaches and conducts research in operations management, logistics, transportation and supply chain management. His current research interests include wireless mobile technologies for supply chain management, adaptive control of supply chains using the digital connection, and risks and sustainability issues in supply chain management.

Nagham El-Berishy is a PhD student at the International Graduate School (IGS) for Dynamics in Logistics at the University of Bremen. She is also a Lecturer in the Department of Production Engineering, University of Alexandria, Egypt, where she received her MSc in Industrial Engineering. In 2010, she was awarded the prestigious German Egyptian Research Long term Scholarship (GERLS 10) to undertake a $\mathrm{PhD}$ research in logistics at the University of Bremen. She is investigating green logistics oriented framework for integrated scheduling of production and distribution networks.

Marion Schulze is a Senior Lecturer in Systems and Operations at Lancashire Business School, University of Central Lancashire, Preston, UK. She earned her PhD in 1997 in Business Studies from Universitaet Lueneburg, Germany. After her PhD she worked for a number of years on ERP projects, as a Systems Analyst for Vattenfall Europe and Senior Business Consultant for PricewaterhouseCoopers in Hamburg, Germany. Her research interests include project management, purchasing and supply, management of identity theft related crimes, management education and enterprise systems. 
Tijjani Abubakar is currently a PhD student at the Lancashire Business School, University of Central Lancashire, UK. Prior to commencing his PhD research he was a Senior Lecturer at Abubakar Tafawa Balewa University, Bauchi, Nigeria. His research interests include sustainability, supply chain management, and performance management.

\section{Introduction}

The nature of ethical theory has long been discussed by numerous authors. The word 'ethics' is derived from the ancient Greek term 'ethikos', which means 'the authority of custom and tradition' (Svensson and Wood, 2003). The Latin translation of this equates to the English word 'moral' (Helms and Hutchins, 1992). Despite the relationship between the origins of the terms ethics and morals, there has been little agreement upon the distinction between the two (e.g., Grace and Cohen, 1998; Weiss, 1942). A number of authors have used the terms interchangeably (e.g., Debeljak and Krkac, 2008; Lange and Fenwick, 2008).

There are five major theories of ethics (utilitarianism, universalism, rights, justice and natural law) that have arisen from continually developing philosophical streams (Helms and Hutchins, 1992). Such concepts stem from ancient writers such as Aristotle and have been continually developed throughout history to the modern day (Trevino and Weaver, 2003). However, these ethical theories need to be translated into actions if they are to be of any practical use. While some see no realistic application for the use of ethics in real-life scenarios, there is a growing body calling for ethical principles to be put into practice.

Despite the subject of ethics originating from ancient history, business ethics in a social science context is a relatively modern construct, only emerging in the early twentieth century (Trevino and Weaver, 2003). Parker (1998) upholds that the ambiguity between good and bad business practices requires ethics to provide guidance to distinguish between the two. Therefore, business ethics is likely to be influenced by prescriptive moral philosophy and the science of business.

Carroll (1991) interprets this distinction from a stakeholder viewpoint, expressing that a business' responsibilities must reflect the ethical expectations of consumers, employees, shareholders and the general local communities. The business' social responsibility must evolve from what society tells the firm the society wants and expects from it (Gold et al., 2010; Ferrel et al., 2012). It is preferable for an organisation to be aligned or ahead of stakeholder expectations, rather than reacting to the current values required from the marketplace. Svensson and Wood $(2003,2004)$ class this as a proactive gap of business ethics performance, which, in the long run, can reap overall business performance benefits.

Business ethics is largely reliant upon the leader to "articulate shared values and develop a vision for the future" [Desmond, (1998), p.6]. If a company is to succeed in achieving fair and moral practices, the onus is upon the leader to provide a clear and consistent culture by foreseeing and curtailing any ethical dilemmas that may occur (Townsend and Gebhardt, 1997; Giacalone and Knouse, 1996). It is therefore necessary to arrive at a balance between corporate objectives and ethical practices (Sen, 1997). The paper is divided into four main sections. The first section on literature review discusses 
the three themes of supply chain and ethics, supply chain ethical practices and the resulting performance from ethical practices. The section on methodology outlines the research questions while the section on results and analysis presents the statistical analysis of the data gathered via a survey by questionnaire. Finally, the conclusion summarises the work done and the contribution as well as implications of the study.

\section{Literature review}

\subsection{The supply chain and ethics}

Since the mid-1990s, supply chains have increased in strategic importance within organisations, principally due to the large amounts of money they are responsible for (Emiliani, 2010). Described as "the series of companies, including suppliers, customers, and logistics providers that work together to deliver a value package of goods and services to the end customer" [Maloni and Brown, (2006), p.36], the supply chain's conduct can have a significant influence upon the performance of a company. More simply, a supply chain can involve the chain of organisations from the supplier's supplier to the customer's customer, and various works have focused upon all aspects of this (Ellram and Cooper, 1993; Novack and Simco, 1991; Jones and Riley, 1985).

Additional value can be created for customers and other stakeholders through effective supply chain practices (Bhatnagar and Teo, 2009). This can help an organisation to differentiate its offer and better serve its customers' needs. As a result, a company may adopt a unique position from its competitors that allows a company to either lower its costs or charge a premium for enhanced services (Hansen and Smith, 2006; Porter and Kramer, 2006). Ethical embeddedness is a particularly effective method of adding value, particularly as supply managers are more likely to face ethical dilemmas on a daily basis compared with managers of alternative functions (Eltantawy et al., 2009; Lindfelt and Tornroos, 2006). With purchasing and logistics having an increasing influence upon the success of an organisation, supply chain ethics has emerged as a key concept that can affect a business' competitiveness.

Ethical responsibility and its impact on supply chain performance has therefore become a prominent issue within business studies and practice. Beamon (2005) posits a simple definition of supply ethics as "the practice of providing goods and services to customers while subscribing to an ethical code”. This is more elaborately described by Eltantawy et al. (2009, p.101) as the act of "managing the optimal flow of high quality, value-for-money materials, components or services from a suitable set of innovative suppliers in a fair, consistent, and reasonable manner that meets or exceeds societal norms, even though not legally required”. This highlights the necessity to act responsibly in all activities from a product's source to the final consumer.

As both purchasing and logistics managers' influence spans a firm's internal functions and external stakeholders, they are in a strong position to affect the organisation's socially responsible activities (Carter and Jennings, 2004). However, it has been noted that there has been little research dedicated to the subject of ethics within supply chains, with only some isolated aspects of supply chains being addressed from this perspective (Svensson and Baath, 2008). In order to expand the knowledge of ethics within supply chains, it is useful to know what drives firms to adopt an ethical stance, 
which practices are being adopted, and the results of acting ethically from both an organisation and stakeholder point of view.

\subsection{Supply chain ethical practices}

As a result of the growing pressures from stakeholders and other parties to act responsibly, there has been a wide uptake of ethical trading initiatives, involving the establishment of minimum standards for social and environmental responsibility within business (Hughes, 2001). More specifically, ethical practices within supply chains have been identified as a powerful means by which social and environmental organisational impacts can be improved (Hall and Matos, 2010). There are numerous facets of supply chain ethics, and prior research has focused upon various aspects of these, including corporate social responsibility (e.g., Andersen and Skjoett-Larsen, 2009), ethical sourcing (e.g., Pretious and Love, 2006), fair trade (e.g., Auroi, 2003) and low carbon initiatives (e.g., Halldórsson and Kovács, 2010).

Eltantawy et al. (2009) indicate that supply chain ethics are largely been concerned with the avoidance of unethical behaviours. As a result, there have been some attempts to establish guidelines that provide direction on sensitive practices such as gift giving or supplier preferences. To be of most use, a firm must carefully choose which practices are most applicable to their strategy, and balance the need for profitable performance with the ethical needs of the stakeholders (Zadek, 1998). This is highlighted in what contemporary business theory refers to as the 'triple bottom line': the notion that companies must take into account their environmental and social performance as well as the traditional bottom line of profitability (Blowfield, 1999). Such practices and initiatives should be evaluated based upon ethical principles, and some of these practices are identified below.

\subsubsection{Corporate social responsibility}

Corporate social responsibility (CSR) is a broad term for an organisation's commitment to operate in an economically and environmentally responsible manner while recognising the interests of its stakeholders (Amaeshi et al., 2008). As a result of the many business and stakeholder pressures earlier discussed, firms are expected to bear responsibility for their full supply networks. Carroll (1991) establishes that CSR has four components: economic, legal, ethical and philanthropic. These obligations must all be fully addressed for any supply chain CSR initiative to be deemed legitimate.

CSR does not have to be a burden upon a company, as its adoption can provide a source of opportunity, innovation and competitive advantage. However, it is important that such initiatives go beyond a glossy media campaign; therefore a coherent and strategic framework for CSR activities is recommended (Porter and Kramer, 2006). CSR was not applied to the supply chain until the 1990s, and it has since been studied in various contexts, including the environment, fair trade, animal welfare and labour and human rights (Maloni and Brown, 2006). Similarly, Carter and Jennings (2004) established that primary supply chain CSR categories include the environment, diversity, human rights, philanthropy and safety; while others focus upon specific aspects such as purchasing responsibilities (known as PSR) alone.

Amaeshi et al. (2008) provide some practical suggestions to translate CSR into managerial actions. These include developing a code of conduct to convey specific 
operational guidelines, permeating an ethical orientation into an organisation's culture, and providing personnel training in ethics and values. Organisational culture is found to affect personal moral convictions about right and wrong in ethical decision making (Carter et al., 2010). Somewhat similarly, various frameworks have been developed to integrate CSR into supply networks and analyse CSR performance (e.g., Cruz and Matsypura, 2009; Clarkson, 1995). It is clear there are numerous aspects of supply chain ethics that have been studied under the umbrella of CSR. It therefore may be more useful to study these individually.

\subsubsection{Codes of conduct}

The first codes of conduct began to appear in the USA in the early 1990s. Of these, perhaps the best known early proponent was Levi-Strauss' code of labour practices following revelations of sweatshop conditions in a contractor workplace in Saipan (Frenkel and Scott, 2002). These codes quickly became widespread, with recent reports suggesting around two thirds of the 100 largest firms in the world operate with a code of conduct (Tulder et al., 2009). Similarly, companies within the UK had become increasingly interested in drawing up a code to clarify their ethical philosophy during this period, giving the document various titles such as 'operating principles' or 'codes of ethics'.

The needs for codes of conduct becomes even greater when supply chains undertake practices such as outsourcing, particularly within developing countries where there is relatively low governance (Tulder et al., 2009). Therefore, in the absence of globally enforced legislation for ethical trading programmes, voluntary codes are developed to implement organisations' own standards of conduct (Hughes, 2001). The use of such codes is clearly of great importance to ensure consistent ethical practices within supply chains and throughout the business as a whole. It is perhaps of no coincidence, then, that codes of conduct have become the most widely touted tool for managing risks within supply networks (Roberts, 2003). These risks include: environment, industry, organisation, problem-specific, and decision-maker related risk factors (Rao and Goldsby 2009).

There has been some debate over the usefulness of codes of conduct, as some believe that these standards are not lived within some firms, and are designed purely to impress customers, suppliers and the public (Donaldson, 1996). Furthermore, there is evidence that codes of conduct may in fact worsen social and environmental conditions for workers, particularly within developing countries by forcing incompatible western values onto a society (Lund-Thomsen, 2008). However, there is evidence that the code is linked to more ethical behaviour and its development represents the most effective way to implement an ethical policy and reduce ethical conflict (Bendixen and Abratt, 2007; Peppas and Peppas, 2000).

\subsubsection{Environment}

Green supply chain management is becoming an increasingly adopted practice among businesses wishing to improve their environmental performance (Testa and Iraldo, 2010). This involves efforts to minimise the negative impact of firms and their supply chains on the natural environment (Mollenkopf et al., 2010). This may alternatively be grouped within sustainable development, and further definitions of the practice have taken into 
account the need to balance competitiveness and profitability with environmental and social considerations, or the 'triple bottom line' (Wolf and Suering, 2010; Hediger, 1999). Such human and social considerations have been given increasing attention, particularly within Europe. There have been numerous attempts to form a balance between performance levels and environmental conservationist measures, with supply chain managers playing a greater role in improving social and environmental impacts of industrial systems (Hall and Matos, 2010; Seitz, 2001).

The ISO14000 series was developed as the environmental management systems (EMS) standard in 1996 based upon the need for improved environmental quality, and its adoption can provide firms with greater environmental legitimacy. Testa and Iraldo (2010) indicate that EMS can be effective tools for the sustainable management of supply chains. There have been various works that have addressed specific environmental practices within supply chains, including waste disposal, recycling, reverse logistics and preferred supplier selection (Maloni and Brown, 2006). Mollenkopf et al. (2010) focus upon the ability of lean initiatives to reduce waste and improve environmental performance within supply chains, and acknowledge the current interest in carbon reduction as an individual component of the broader environmental management realm.

The transition towards a low carbon economy is reliant upon the reduction of greenhouse gas emissions through reducing energy consumption and the use of renewable resources. Although this is of the utmost importance within logistics and the supply chain in practice, it does not appear to have received corresponding attention within the literature (Halldorsson and Kovacs, 2010). Online retailing has been recommended as a method to reduce the 'last mile' carbon footprint, as it has been revealed that the carbon emissions from car-based shopping trips can far exceed those from distribution operations through the length of the supply chain (Edwards et al., 2010). Environmental concerns within logistics are of particular importance as it is often regarded as the missing link in the provision of green products and services to consumers (Wolf and Suering, 2010).

Porter and van der Linde (1995) make a strong case for the adoption of green initiatives, indicating that the discharge of scrap, harmful substances and energy forms into the environment as pollution is an indication that resources have been used incompletely, inefficiently or ineffectively. To this extent, innovative approaches are recommended to minimise waste and improve productivity to address the root causes of pollution, such as reduction of unnecessary packaging and simplifying designs. In addition, the growing worldwide environmental and ethical awareness re-enforces the paradigm shift from firm level to supply chain level competition with the resultant challenge and need to incorporate comprehensive supply chain-wide sustainability goals (Gold et al., 2010).

\subsubsection{Labour and human rights}

Following a number of high profile cases of 'sweatshop' labour conditions in suppliers to global brands such as Nike and Wal-Mart, issues such as child and forced labour, health and safety, discrimination, pay and working conditions have become increasingly prominent in modern supply chains (Maloni and Brown, 2006). The global supply chain practices of numerous firms have been criticised as being exploitative, and under such scrutiny it is necessary for businesses to focus attention on their corporate culture, management and labour practices. It is suggested that this is coupled with appropriate 
codes of conduct to avoid the association with any exploitative practices at any point within the supply chain. In particular, benefits from social and environmental codes include both improved worker health, leading to greater worker productivity and lower medical bills; and the promotion of long term business viability through environmental sustainability (Collinson, 2001).

Winstanley et al. (2002) suggest that there are a range of responses to managing human rights, from inaction to full involvement. However, ignorance and indifference to such situations are becoming increasingly unacceptable, therefore a targeted and focused strategy to eliminate practices such as child labour is required if a firm is to thrive. It is suggested that multinational enterprises must abide by the following duties if they wish to avoid potentially damaging breaches of human rights: adhere to the local labour laws, refrain from coercion, meet minimum health and safety standards and pay workers a living wage. In addition, domestic labour rights must also be protected, and Ciscel and Smith (2005) suggest that flexible production systems have meant that workers within supply chains must be similarly flexible. This has led to fragmentation, disorientation and chaotic personal lives, and must be minimised if an organisation is to attain basic ethical standards.

\subsubsection{Procurement}

According to Preuss (2001), the function of procurement involves the acquisition of materials, services and equipment used in the operation of an organisation. Its strategic importance to an organisation has recently grown in significance, particularly due to the large budgets the function is responsible for. Furthermore, buyers are often the key linkage between the firm and its external environment, and as a result, they are seen as 'custodians' of the public and stakeholder interest (Bendixen and Abratt, 2007; Hughes, 2001).

As a result of the many drivers of organisational and supply chain ethics, socially responsible procurement emerged in an attempt to take into account the public and environmental consequences of buying (Drumwright, 1994). Arbuthnot (1997) identified a number of practices that were associated with unethical experiences, the most significant being misleading vendor practices. Similar unethical practices have since been highlighted, including favouritism, preferential treatment and bribery (Carter, 2000), and deceptive tactics within negotiations (Reitz et al., 1998). The tradition of gift-giving has been subject to widespread disapproval, and in an early study by Brennan et al. (1961), it was found that the majority of executives regard this as unwise practice. Various studies have since found that purchasers view both offering and accepting gifts as unethical (Razzaque and Hwee, 2002), although this may sometimes be dependent upon the value of the gift (Trawick and Swan, 1988). However, there may be a cultural aspect to gift-giving to which purchasers must be sensitive. Therefore a clear distinction must be made between gift-giving within practices such as Guanxi (a Chinese custom concerned with the building of relationships) and bribery.

\subsubsection{Fair trade}

There has been steady growth in the fair trade movement within recent years, particularly within the food retailing sector. This is part of a wider regulatory framework, whereby product or organisational certification can be achieved for addressing ethical 
consumption issues. Others labels include 'dolphin friendly' tuna, Rugmark (denoting rugs made without the use of child labour), and sustainable timber products (certified by the Forest Stewardship Council) (Low and Davenport, 2005). Such certifications are of importance within supply chains to provide assurance that products and materials originate from sustainable sources. By ethical trading, a company takes responsibility for the social and environmental performance at other stages of the chain, especially for that of the primary producers. This is a significant change from traditional practice as it means a company takes responsibility for the behaviour of others even if it does not have any long-term formal liability for their actions (Blowfield, 2004).

Fair trade's aim is to encourage community development and empowerment at the source of supply chains by applying a fair trade supply agreement. The application, monitoring and enforcement of the agreement is independently audited by a national body (such as the FairTrade Foundation in the UK), ensuring minimum prices and conditions are consistently achieved (Davies and Crane, 2003). Auroi (2003) states that fair trade is an example of good practice as it has a balancing effect upon supply chains, proving that production and trade can be managed in a more sustainable way. However, the author acknowledges that fair trade alone is unlikely to expand the sustainability of supply chains due to complexities within the distribution, so supports its use within the scope of an organisation's codes of conduct.

This view is corroborated by others, as it has been reported that certified suppliers often lack consistency in volume and quality (Maloni and Brown, 2006). Equally, the fair trade message is unlikely to be fully absorbed by consumers, who are more likely to focus upon price and quality when making purchasing decisions. This has caused many fair trade products, such as coffee, to act as loss leaders in retail stores (Low and Davenport, 2005). Therefore, the challenge for supply chains is to provide high quality greener and more sustainable alternatives at prices customers will pay (Carrigan and Pelsmacker, 2009). This will have the overall advantage of improving a company's reputation and alleviating public criticism.

\section{Performance resulting from ethical practices}

Over the past decade, managers and researchers alike have recognised the potential benefits that supply chain ethical responsibility has on business performance (Eltantawy et al., 2009). Commercial benefits can be achieved as side effects from the implementation of ethical initiatives, and these act as an important motivator for organisations to act responsibly (Testa and Iraldo, 2010). Performance can be judged by numerous indicators, both tangible and intangible, using various measures.

Many studies have determined that direct financial benefits can arise from the adoption of ethical initiatives. For instance, Bowman and Haire (1975) found that firms with some social responsibility prose achieved a greater return on equity than those with none, while Waddock and Graves (1997) indicate that the better companies perform socially, the greater the financial returns. Similarly, argued that social responsibility and financial performance are linked.

However, there have been studies with results to the contrary, with some finding no relationship between supply chain ethical responsibility and profitability (e.g., McWilliams and Siegel, 2000). Despite this, many indirect links between ethical 
responsibility and financial performance have also been found. Maignan et al. (1999) refer to survey findings that revealed that $88 \%$ of consumers are more likely to buy from a company that is socially responsible, and Porter and van der Linde (1995) indicate that the costs of addressing environmental concerns can be eliminated through innovation that can simultaneously deliver overall performance gains. Such changes can lower costs, and improve product quality and global competitiveness. Similarly, Porter and Kramer (2006) establish that efficient utilisation of resources can make a business more productive, lower internal costs and attract new customers. This indicates that there are other ways supply chains, and ultimately businesses, can profit from ethical responsibility.

Improved product quality has been identified as additional benefit associated with supply chain ethical behaviour. Stainer and Stainer (1995) believe that ethics nurtures quality, resulting in a positive relationship between productivity, quality and ethics. This finding was echoed by Helms and Hutchins (1992), who report that the production of good quality products is ethical in itself, while poor quality products can negatively impact a company's market share, its profits and all of its stakeholders. Improved product quality, along with corporate social responsibility and other ethical initiatives may help to strengthen a firm's reputation for being reliable and honest by meeting the expectations of key stakeholders (Roberts, 2003).

Positive reputations have often been linked with positive financial returns, so the public's perception of a supply chain's conduct is of great importance. Eltantawy et al. (2009) stress that ethical responsibility is essential to the supply function's perceived reputation, which in turn has an indirect effect on supply chain performance. The ethical actions that create a positive reputation can further lead to greater customer loyalty and retention, while providing an excellent tool for the motivation of employees (Maignan et al., 1999). A good reputation is therefore a significant intangible benefit of ethical supply chain management.

Despite the apparent importance that reputation has to business performance, customers have been shown to have a low awareness of both ethical and unethical organisational behaviour, particularly in view of the increased media attention on company activities in recent years (Boulstridge and Carrigan, 2000). It was later discovered that consumers are more concerned by ethical issues if it has an impact upon their quality of life (Carrigan and Pelsmacker, 2009). Therefore, it may be wise for supply chain managers to take into account the stakeholders that are likely to be directly affected by their actions, such as local communities, when deciding upon ethical initiatives.

Through acting more ethically, an organisation can strengthen its working relationships along supply chains. The existence of strong relationships between an organisation and its suppliers and distributors is recognised as an important factor in developing a sustainable competitive advantage, and therefore an additional benefit of supply chain ethical behaviour (Bendixen and Abratt, 2007). This was similarly reported by Valenzuela and Villacorta (1999), who indicate that ethical, cooperative relationships between companies and their suppliers result in higher competitiveness and a greater creation of wealth. Equally, though, ethical behaviour may be beneficial through the avoidance of the negative consequences that unethical behaviour may bring. Firms who make poor, self-centred decisions are likely to suffer from eventual financial hardship (Svensson and Wood, 2004). By acting more responsibly, organisations therefore do not take any unnecessary risks with their performance or reputation. 


\section{Methodology}

\subsection{Research questions}

It has been shown that the effective management of the supply chain is necessary to increase the profitability of the company. Overall success is often the result of a rapid response to customer requirements and the maintenance of a positive company reputation. As consumers consider the ethical reputation of a company when making product decisions, it is necessary for an organisation to meet these requirements to remain competitive. This may mean that the extent to which ethical practices are adopted within a supply chain is dependent upon the expectations of the customers.

However, there are many other drivers that have been identified, including the media, legal regulations and internal organisational improvements. Government regulations imposed on the profession were perceived as least likely to result in a climate of high ethical behaviour (Douglas and Swartz, 2009). It had previously been indicated by Carroll (1991) that a business must select the stakeholders with the most legitimate claim to the organisation. Therefore, it would be useful to be aware of the most influential driving forces of ethical supply chain initiatives to aid the prioritisation of ethical business objectives, particularly in light of that fact that many customers are unaware of most high profile ethical an unethical behaviours. For this reason, the initial research question will enquire:

1 What are the main factors that drive supply chains to act ethically?

There are clearly many different practices that can be adopted within a supply chain to help a company augment their ethical responsibilities. Various initiatives have been described in the literature, from broad schemes such as corporate social responsibility and sustainable development, which may cover a wide range of individual practices; to more specific techniques including codes of conduct, purchasing policies and various certifications (e.g., ISO14001, fair trade, FSC or Rugmark). The utilisation of such initiatives within the supply chain can help to improve the social and environmental impacts of an organisation as a whole, so the final approach must be chosen carefully.

To maintain the balance between profitable performance and the requirements of the stakeholders, supply chain managers must identify the ethical practices that are most relevant to their strategy from the vast array that are available. As a result, it would be useful to ascertain which of these are primarily utilised in practice within various industries. This may also be of use from a competitive stance, as initiatives that are standard and acceptable within one sector may be completely inappropriate in another. This will provide a valuable starting point when deciding upon the applicability of various ethical practices. Hence:

2 What are the primary ethical practices that exist within supply chains?

3 Does this vary between industries?

According to Eltantawy et al. (2009), it appears that the effect of adopting ethical practices on supply chain performance has received relatively little attention in the literature. It is important for supply chain managers to consider the triple bottom line of 
profitability, environmental and social performance when instigating ethical actions. However, mixed reports have emerged on the effect of ethical practices upon organisations’ financial performance.

Other benefits have also been shown to arise as a result of various ethical initiatives, from improved product quality to strengthened partnership relationships within supply chains. There are numerous tangible and intangible effects that may indicate the success of specific ethical practices, so these must be considered rather than measuring financial returns alone. To assist supply chain managers in the identification of suitable techniques to reinforce their ethical responsibilities, an understanding of the relative effectiveness of each would be required. Similarly, through underestimating the importance of ethical responsibilities, a business may suffer considerable disruption. It is important to find methods that maximise the triple bottom line while avoiding any organisational conflict, leading to the questions:

4 Do ethical supply chain practices improve business performance?

5 Which practices are most beneficial to business performance?

Furthering the identification of business benefits from implementing ethical initiatives within the supply chain, Waddock and Graves (1997) had discovered that that more an organisation invests into such practices, the greater the financial return. Conversely, the authors also found that the better an organisation performs financially, the better their social performance. Therefore, a virtuous cycle, whereby the more a company invests in ethical initiatives, the greater the returns, the greater the investment et cetera, is posited. Based on this notion, it is possible that the greater the extent of ethical implementation within the supply chain, the greater the resulting performance. Consequently, it is necessary to investigate the following:

6 Is there a relationship between the extent that ethical initiatives are utilised and the degree of performance obtained?

There has been some indication that the recent global recession may have affected both the consumers' desire to purchase ethically and business' ability to implement ethical practices. In times of financial hardship, perceived ethical responsibilities may be reduced as the need to lower costs becomes a greater priority. However, studies in this area, such as Carrigan and Pelsmacker's (2009), have been sparse and mainly conceptual. Although this has notion not been thoroughly investigated, it may suggest that the extent to which ethical practices are adopted is dependent upon external forces and may change over time.

If the extent of an organisation's ethical responsibilities is changeable over time, it would be useful to know if there have been any changes in the adoption of ethical practise during pre-, mid- and post-recession periods. This will further enable supply chain managers to develop a suitable range of ethical practices and techniques during this period. The final research question therefore queries:

7 How has the adoption of ethical practices changed over time? 


\subsection{Data collection}

\subsubsection{Response rate}

Of the 200 questionnaires posted, 21 replies were received by mail. The outstanding respondents were telephoned two weeks later, and a further 52 responses were recorded directly via this medium. This increased the overall response rate to $36 \%$. Organisations from the food sector originally accounted for a quarter of the sample, however a disproportionately small response was received from this sector, at less than $4 \%$ via both mail and telephone. Because of this, the data is now only able to represent clothes, household and electrical retailers, wholesalers, manufactures and distributors when comparing the results by sector. The responses that were received from the food sector will be included in total results examination, however.

\section{Results and analysis}

\subsection{Demographic data}

Table 1 indicates that the majority of responses were obtained from small to medium enterprises, with $65 \%$ of organisations employing 50 or fewer employees and $49 \%$ with an annual turnover of under $£ 2$ million. As no responses were received from companies with 501-1,000 staff or a turnover of £26-50 million, the results may not be representative of organisations within these groups.

Table 1 Profile of respondents

\begin{tabular}{lc}
\hline Demographic characteristics & Percentage \\
\hline Number of employees & 5 \\
$1-50$ & 25 \\
$51-250$ & 3 \\
$251-500$ & 0 \\
$501-1,000$ & 7 \\
$1,001+$ & \\
Annual turnover & 49 \\
Less than £2 m & 27 \\
$£ 2$ m-£10 m & 7 \\
$£ 11$ m-£25 m & 0 \\
$£ 26$ m-£50 m & 17 \\
$£ 51$ m+ & \\
Business sector & 32 \\
Household & 32 \\
Electrical & 31 \\
Clothing & 5 \\
Food &
\end{tabular}




\subsection{Driver of ethical supply chain practices}

The following diagrams represent the most frequently indicated forces that drive organisations to adopt ethical supply chain practices (ESCPs). These drivers are shown in Figure 1 and broken down by sector in Figure 2 .

Figure 1 Most prevalent drivers (see online version for colours)

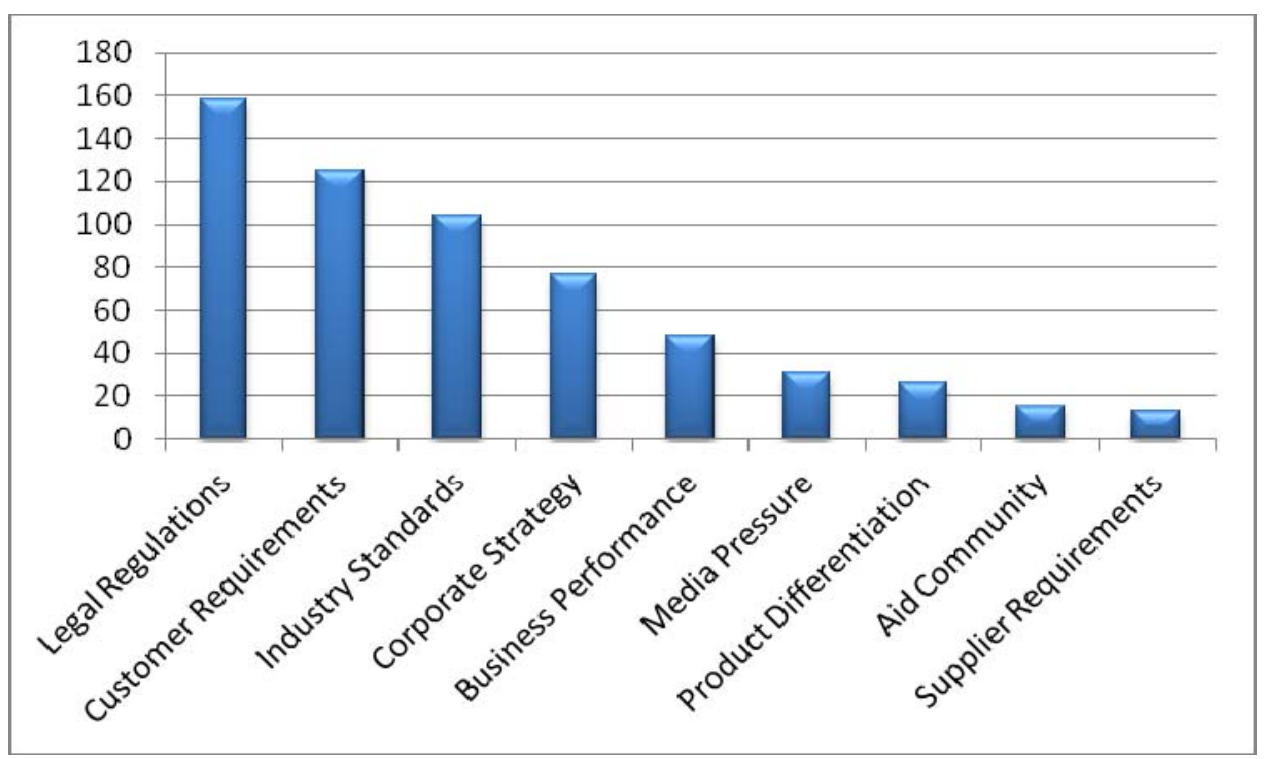

Figure 2 Drivers per sector (weighted) (see online version for colours)

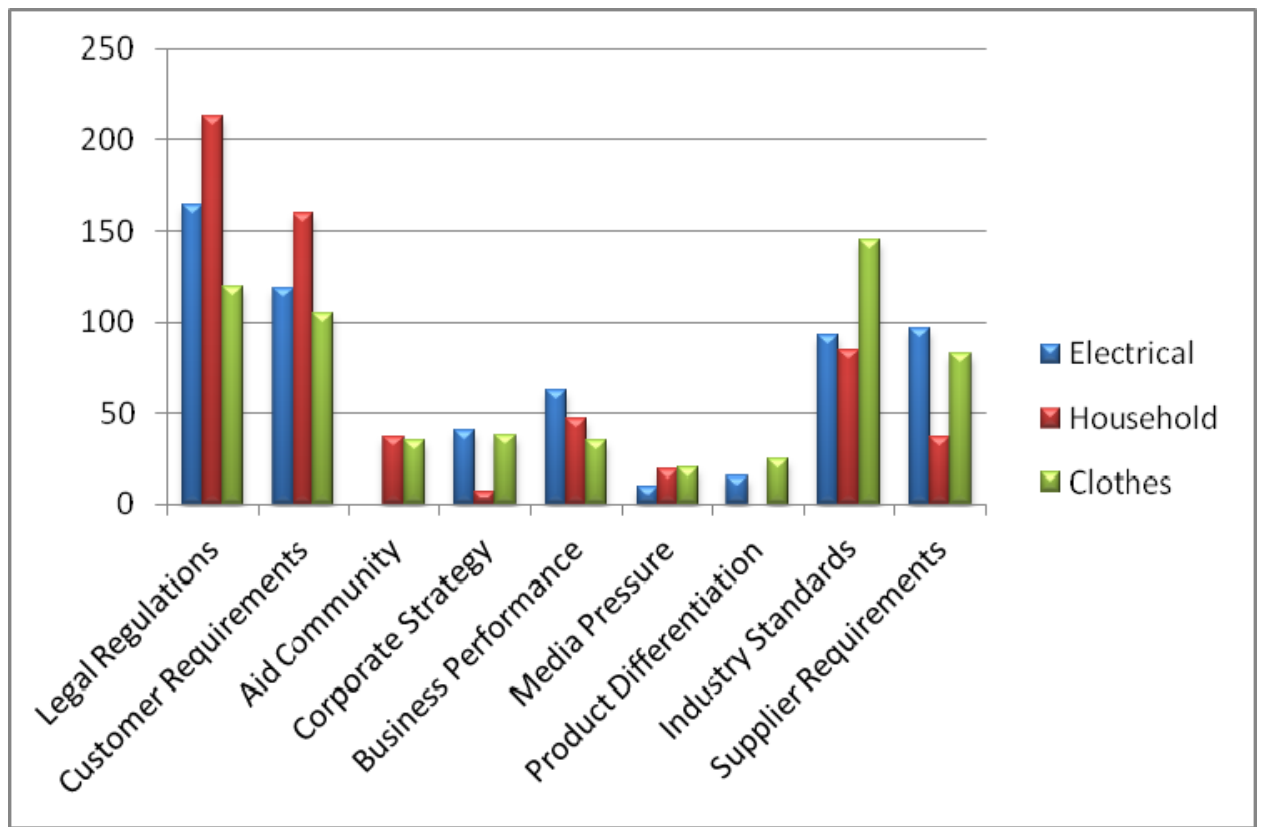


Abiding by legal regulations was identified as the primary reason for adopting ESCPs. While legal regulations, customer requirements and industry standards are the most common reasons for adopting ethical practices within supply chains overall, there are some variations within specific industries. Significantly, industry standards are the most important driver within the clothing sector, unlike household and electrical sectors which both cite legal regulations as the predominant driving force. Few organisations cited aiding the community and the requirements of suppliers and distributors as a strong reason for adopting ESCPs.

\subsection{Ethical practices}

Overall, 22\% of the surveyed organisations indicated that they are currently certified by a regulatory body. Interestingly, there is some variance in the proportion of companies certified between individual sectors, as shown in Figure 3.

The electrical and, in particular, the clothes sector have a very small incidence of certified companies, at just $16 \%$ and $11 \%$ respectively. The household sector, however, heavily increases the average, with $37 \%$ of organisations in this sector possessing certification.

Figure 3 Companies with certification (\%) (see online version for colours)

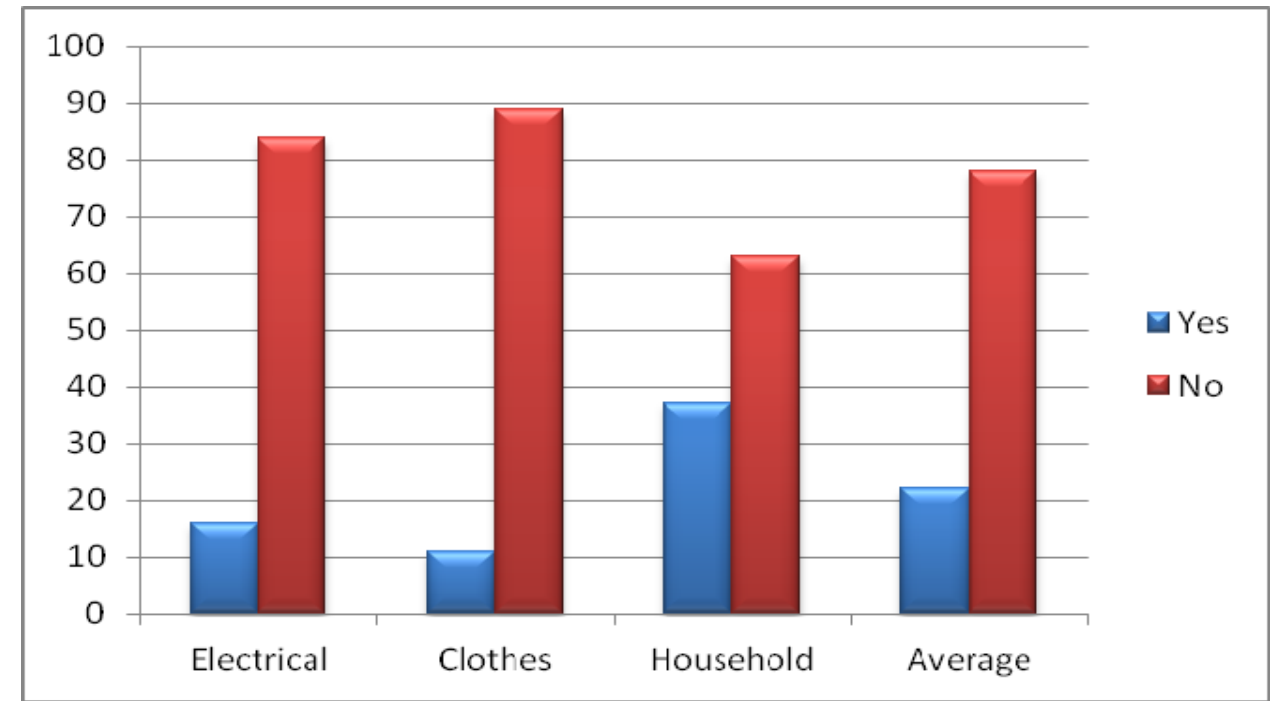

Of the many practices that can be adopted that are classified as 'ethical', the following diagrams show which of these practices are most prevalent and to what extent they are implemented within supply chains from various sectors. Health and safety practices are adopted by nearly all organisations within the sample, with $88 \%$ indicating implementation, followed by child labour and responsible procurement at $74 \%$ and $69 \%$ respectively. Environmental management systems such as ISO14001 and offering incentives for ethical actions were the practices with the lowest uptake, with only 33\% and $15 \%$ of organisations utilising these. 
Figure 4 Percentage ESCP adoption - all sectors (see online version for colours)

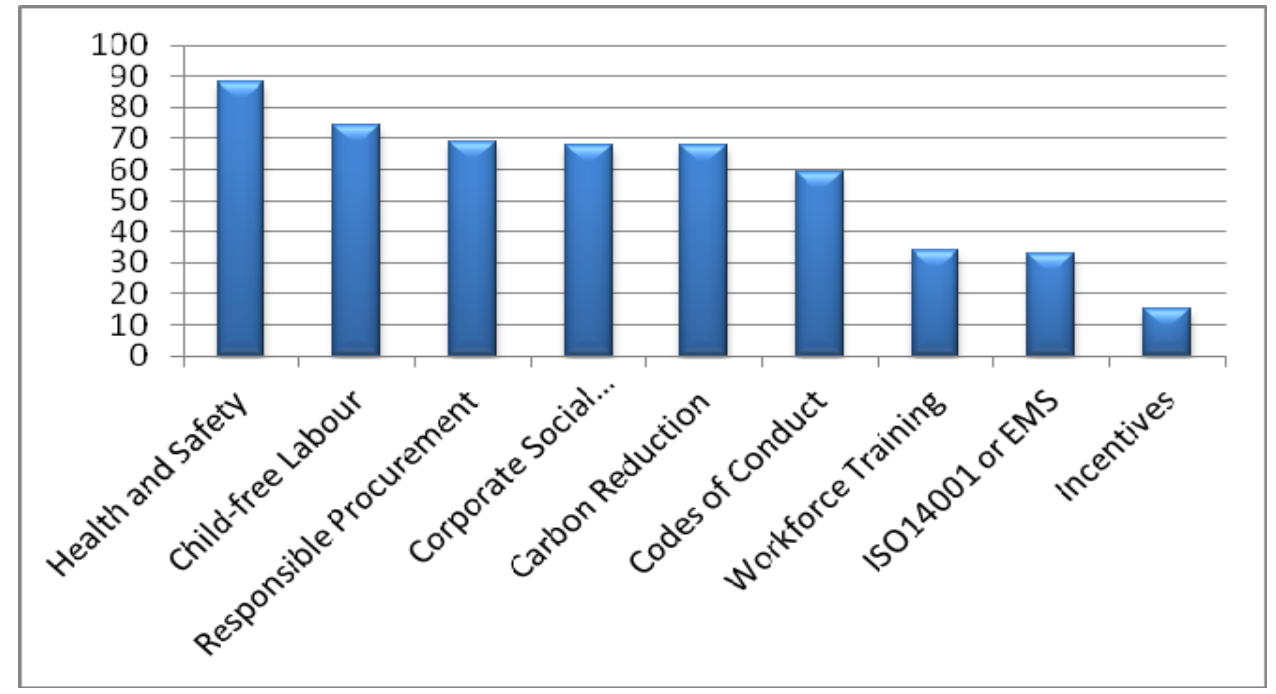

The companies were additionally required to denote the extent to which each ESCP was implemented within the organisation (Figure 4). This was conducted on a five-point scale ranging from full implementation to no implementation. To ascertain the overall extent of ESCP implementation, a score of four was given to every fully implemented ESCP, decreasing to zero for no implementation. The scores were then totalled for each organisation. As there are nine individual practices being investigated, the maximum score for ESCP implementation is 36 . The closer the respondent is to this score, the more fully the organisation has committed to implementing the surveyed practices.

Figure 5 Extent of ESCP adoption by sector (see online version for colours)

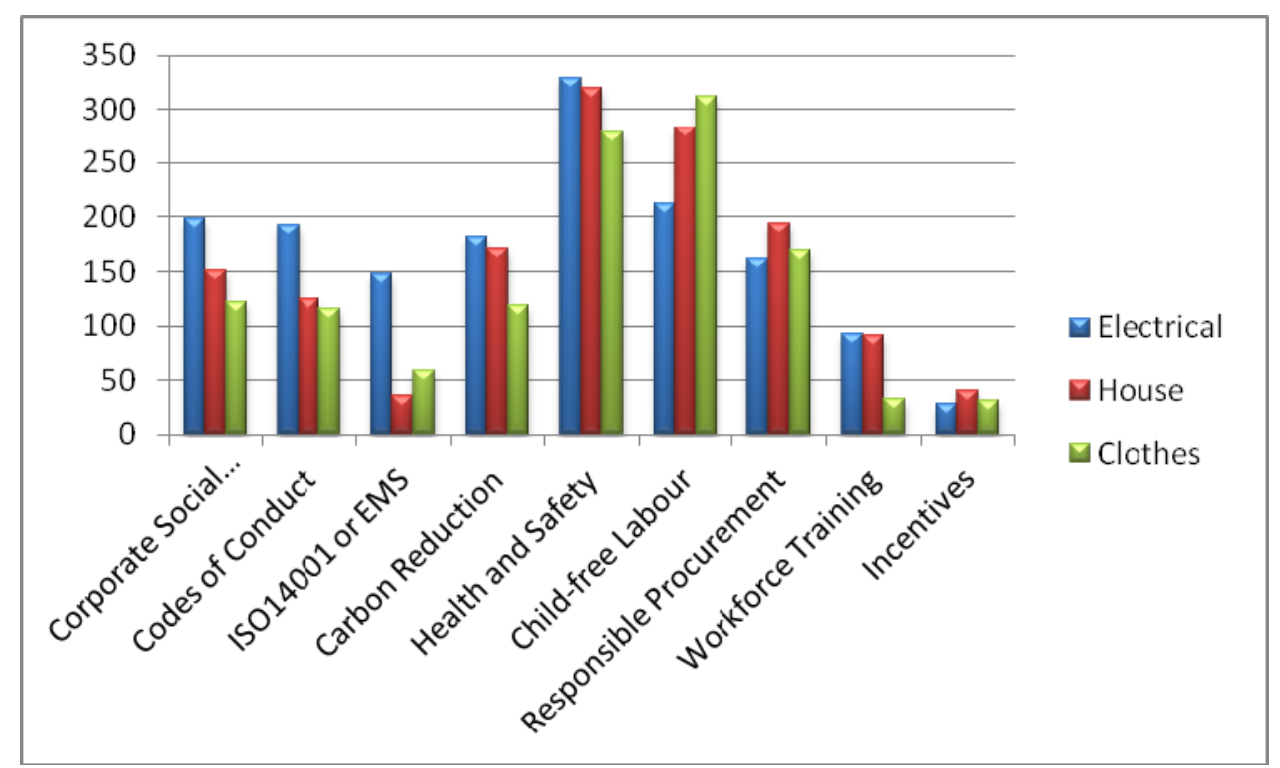


The extent of ESCP implementation within organisations is illustrated in Figure 5. Health and safety practices, enforcement of child-free labour and socially responsible procurement are implemented to the greatest extent. However, child-free labour is most strongly enforced within the clothing sector.

In addition, environmental management systems such as ISO14001 are most thoroughly implemented within the electrical sector, with organisations within the sample scoring 148 points on average. This is in stark contrast to the remaining sectors, with clothing and household-related businesses scoring 59 and 35 points respectively. Incentives are the least utilised and implemented ESCP within all sectors (Figure 6), and only a very small minority of organisations have adopted this.

Respondents were asked to denote the extent to which ESCPs were implemented both five years ago and five years in the future. It was found that carbon reduction has been the most increased ethical initiative implemented in supply chains over the past five years by a considerable margin. Although workforce training and incentives appear to also have a large percentage increase in adoption, the overall number of organisations that adopted these practices is very small, as seen in Figures 4 and 5. This is equally applicable to the apparent future decrease in the adoption of incentives, however this figure is distorted due to the low number of organisations adopting this practice.

Environmental concerns appear set to continue over the subsequent five years, with a continued increase in carbon reduction initiatives (although at a less rapid rate than previously) and environmental management systems implementations.

Figure 6 Percentage change in the extent of ESCP implementation (all sectors) (see online version for colours)

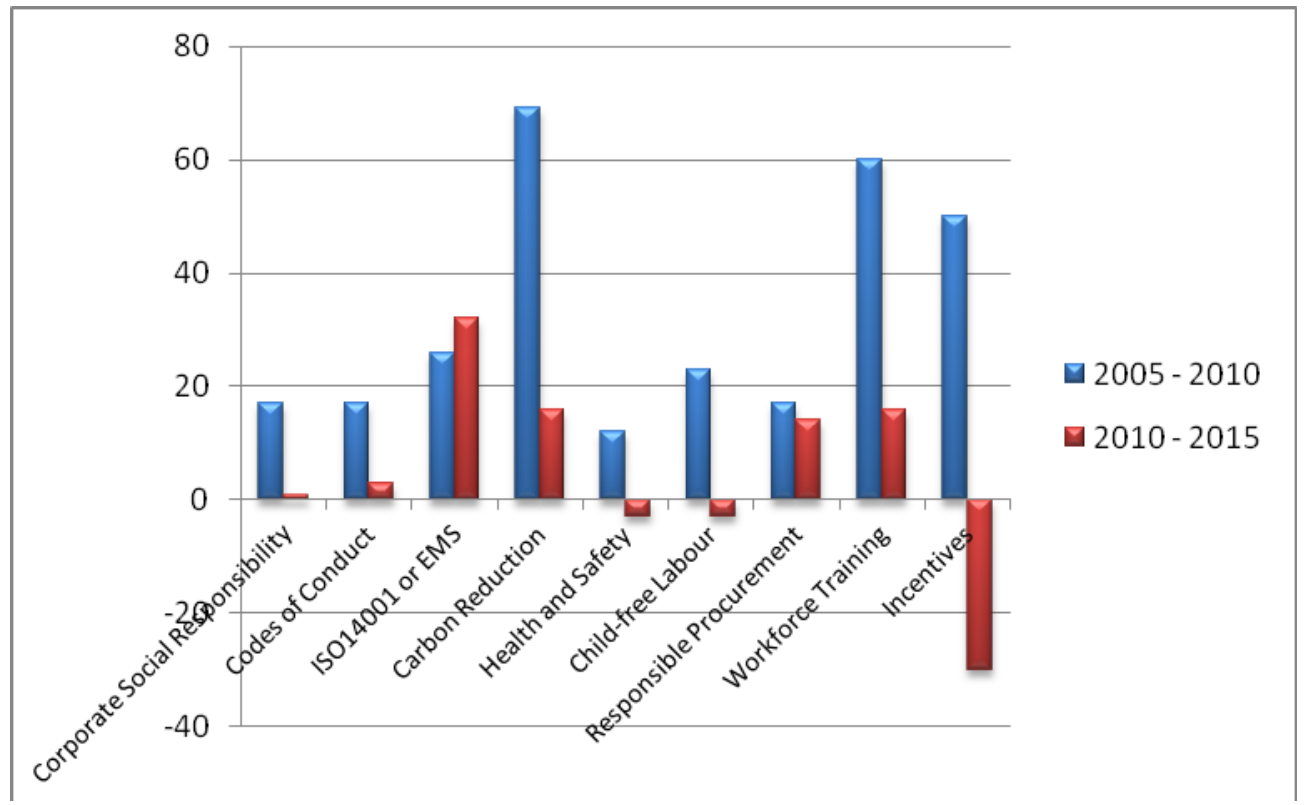




\subsection{Performance benefits}

In total, 58\% of companies reported that business performance had been improved by the adoption of ESCPs. Of the majority that achieved improvements, reputation is clearly the most frequently cited advantage gained, as shown in Figure 7.

Figure 7 Percentage of companies that achieved improvement (see online version for colours)

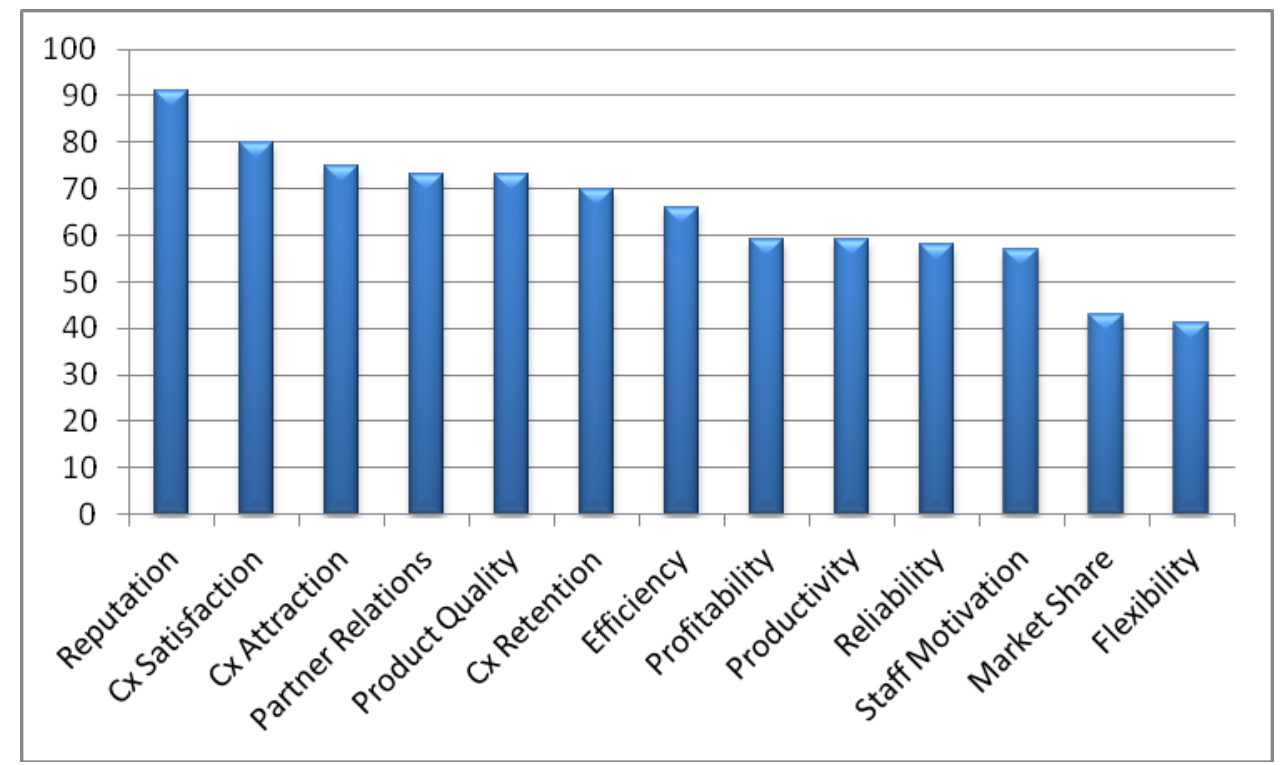

Figure 8 Weighted benefits from ethical practices (see online version for colours)

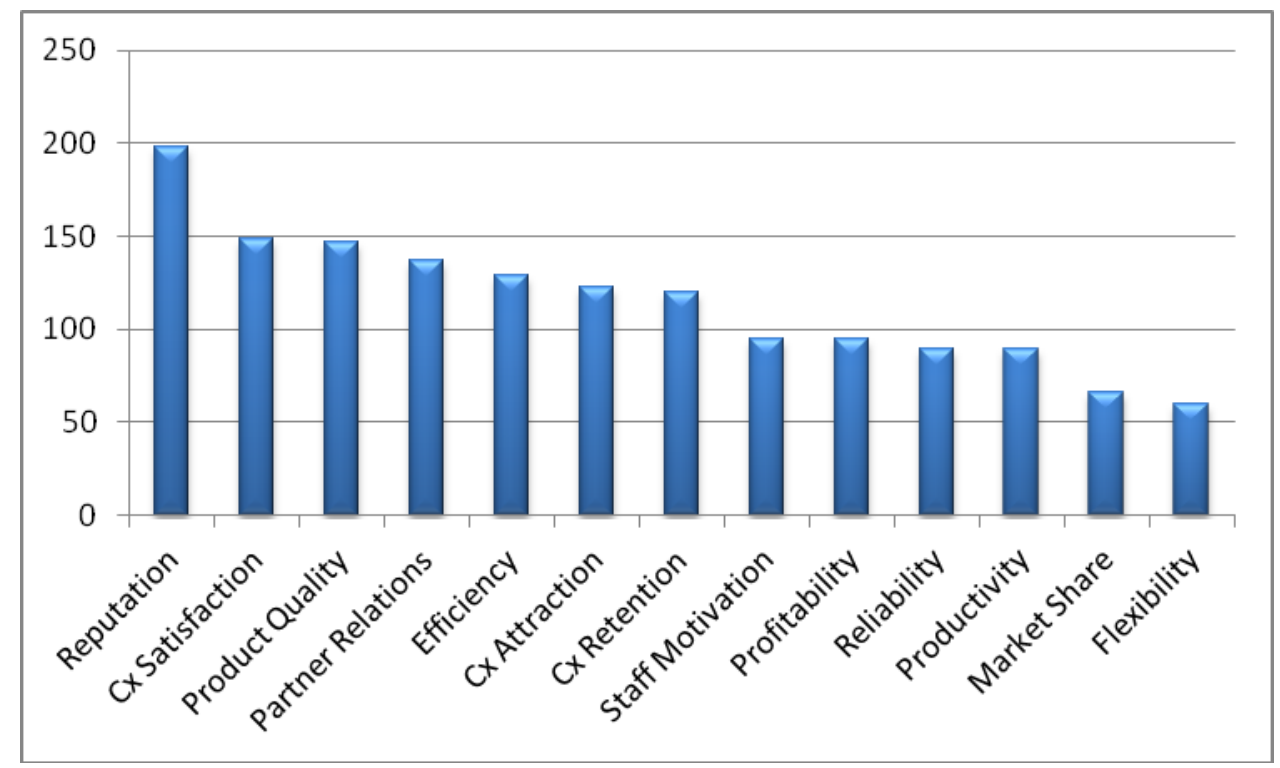


Again, responses to the extent of performance benefit experienced were indicated on a five-point scale, so were given a corresponding score to ascertain the degree of improvement. The average weighted benefits are shown in Figure 8.

Not only are reputation and customer satisfaction the most frequently achieved benefit, these performance indicators also have the greatest degree of gain. However, while increased customer attraction was achieved by numerous organisations, this is felt to a lesser degree. Therefore, many companies have attained a small extent of customer attraction improvements from the implementation of ESCPs. Market share and flexibility are both experienced by the fewest number of organisations and to the smallest extent. Staff motivation appears to have the greatest disparity, with few companies indicating an improvement in this area, but to a great extent.

It is necessary to note that, while improved reputation and customer satisfaction were found to be the most frequent and substantial benefits overall, organisations within the clothing sector were most likely to achieve efficiency gains as the primary benefit of ESCPs, with customer satisfaction rated much lower.

The weighted ESCP and the weighted performance benefits for each company that was surveyed are plotted on a scatter diagram to attempt to identify any relationship between the two. This is illustrated in Figure 9. As before, this was achieved by awarding a score of one to four for each ESCP and performance measure depending on the extent that was indicated. The maximum score that could be achieved for ESCP implementation (i.e., all practices fully implemented) is 36; the maximum score for performance (i.e., all performance indicators have the greatest gain) is 52 . The trend line was automatically calculated and plotted by the Microsoft Excel programme.

Figure 9 Relationship between extent of ESCP adoption and extent of benefits (all sectors) (see online version for colours)

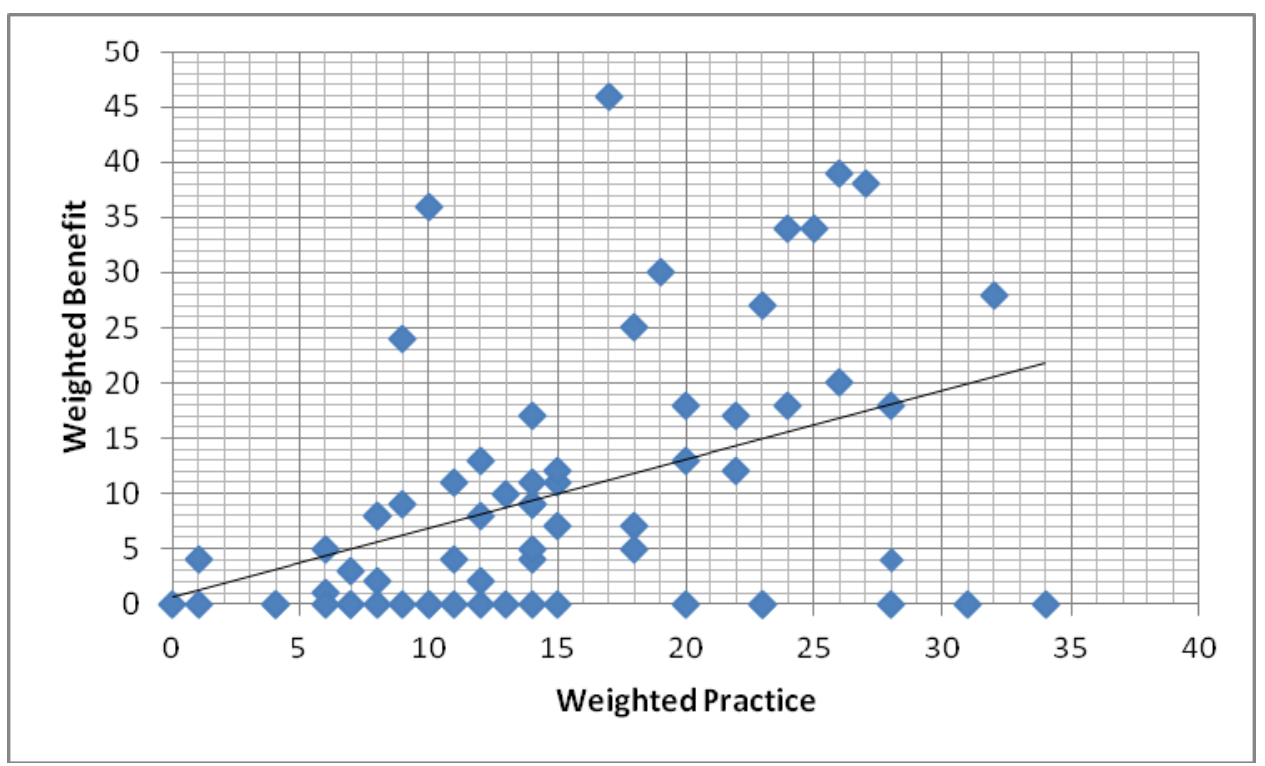

As Figure 9 shows, there is a positive correlation between the extent that ESCPs are implemented and the extent of benefits achieved, and this is indicated by the trend line. However, there are some notable exceptions to this trend, such as the five organisations 
that have implemented ESCPs to a great extent (weighted over 25), but have achieved no benefit, and the few organisations that achieved very high benefits with only minor ESCP implementation. These may be because of the random nature of the results, anomalies in the data collected, or could be representative of a wider trend. It is impossible to know this without conducting further statistical investigations on the data. It is apparent that organisations within the sample that indicated a very low implementation of ESCPs (weighted between 1 and 9) also achieved very minor benefits (weighted between 1 and 9).

Additionally, the mean weighted ESCP implementation and performance of the sample is also measured in companies with and without certification (Figure 10) and by company size (Figure 11) to establish if any connection exists between these parameters.

Figure 10 Average ESCP and performance for certified and non-certified companies (see online version for colours)

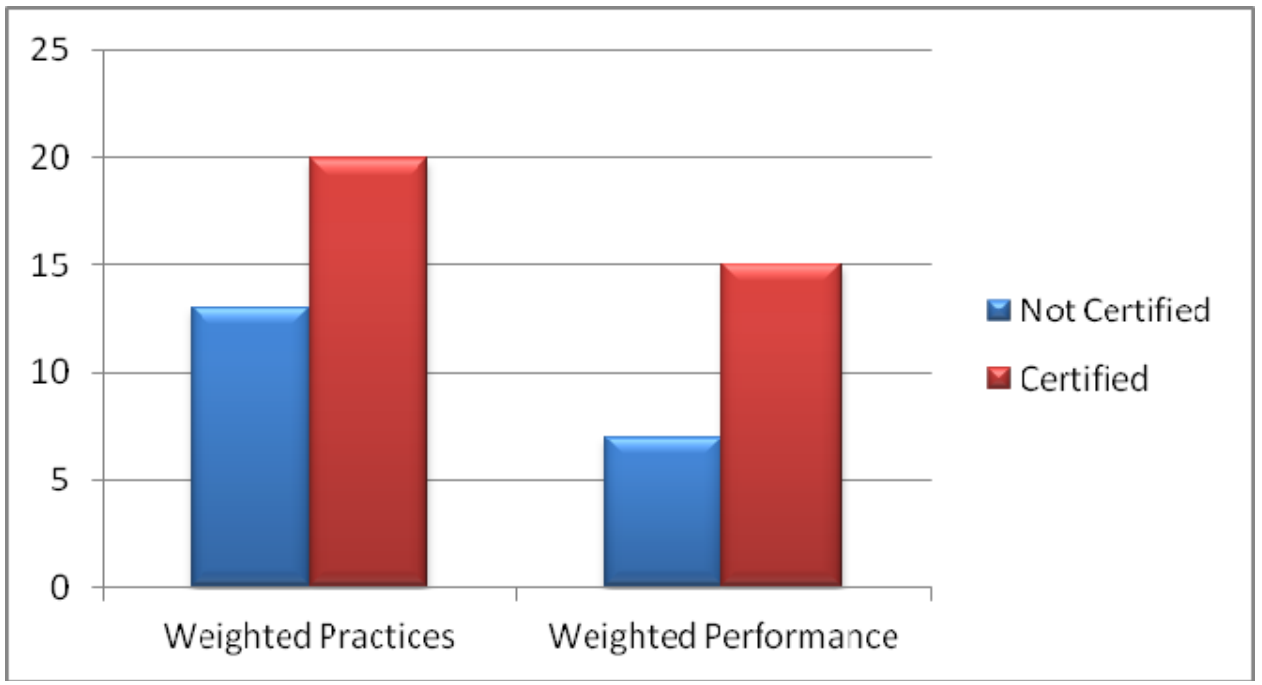

It is clear that organisations within the sample that are certified by a regulatory body are likely to implement ethical practices to a greater extent, and are likely to get greater benefits from this. On average, these companies scored 20 points for the extent that ESCPs were implemented and 15 points for the extent of performance subsequently gained. Organisations without certification show a similar pattern to those with certification, but ESCP implementation and performance are achieved to a much lesser extent, reducing to 13 points for ESCP implementation and seven points for the performance. It appears that, within the sample, certification increases the extent of ESCP implementation by $54 \%$ and increases the extent of performance by $53 \%$.

The organisations within the sample were chosen at random and therefore should represent the wider population. However, the number of respondents from the 251-500 and 501-1,000 employee categories were too small to make any reasonable comment upon (see Table 1). For this reason, only the three remaining categories were used in Figure 11. The extent that ESCPs are implemented in these companies appears to increase with the size of the company from the data that was obtained. Surprisingly, the benefits obtained from this do not increase correspondingly, as the 1,001+ employee 
category illustrates. Although ethical practices appear to be well established within large organisations, the benefit that is gained is relatively low.

Figure 11 Average ESCP and benefits by company size (see online version for colours)

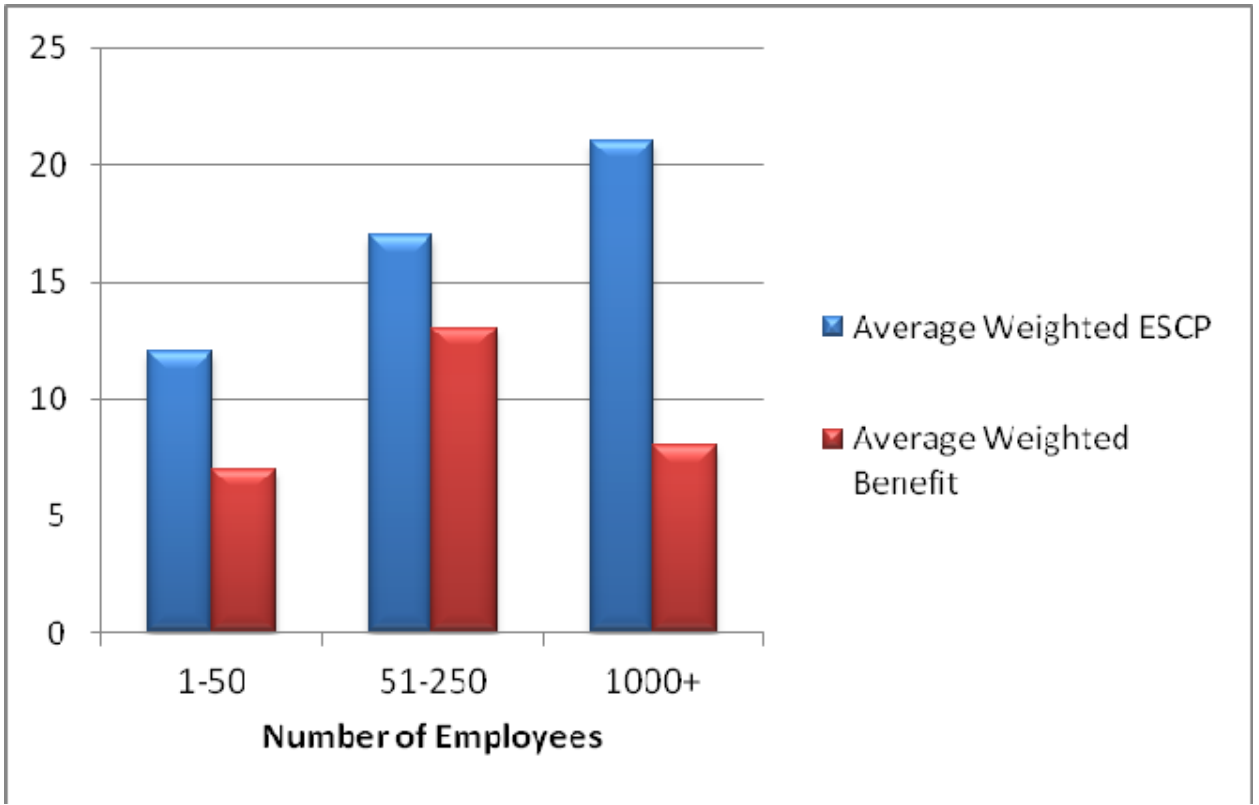

\section{Conclusions}

The presence of many ethical practices was observed throughout the supply chains of nearly all the studied organisations, and their existence is likely to have positive effects on company performance.

Supply chains are most likely to act ethically because of the legal requirements that are expected of them, explaining the extremely high incidence of health and safety practices. However, competitive pressures are also highly important, therefore industry standards and consumer trends must be closely monitored and practices altered accordingly.

Ethics and ethical practices may be of particular relevance to buyers, suppliers and distributors, therefore it is essential that these groups are at the forefront of any changes. Similarly, organisations that are associated with products that have a high environmental profile must be vigilantly managed due to the increased scrutiny from stakeholders. Similar high stakeholder pressures are felt within large organisations, so the implementation of ESCPs is evidently not a choice for these companies.

Not only do ESCPs improve profitability, but the greater the extent of practice implementation, the greater the subsequent rewards will be. The initial costs of implementing ethical practices must not deter SMEs from the use of ESCPs. Low investments will result in low returns and possible losses. Therefore, ethical embeddedness may be of a particular importance within these companies. 
All ESCPs have witnessed an increase in implementation over the last five years, especially regarding the environmental aspects of operations. To continue this trend, it is recommended that companies continue to invest in environmentally viable practices. The use of environmental management systems is likely to significantly grow in the near future but further research would be useful in this area. Further, a major area of future research challenge is on managerial tools and methodologies for the deployment of ESCPs within firms and across supply chains. The concept of supply chain ethical champions need to be investigated with respect to the focal organisations within the chain and the moderating influence of the span of control of such focal organisations on the span of ethical practices that can be achieved.

Ethical practices appear to be a powerful means to reduce social and environmental impacts while simultaneously improving performance, validating the increased prominence of the 3BL. Even organisations that have not achieved a specific benefit from the utilisation of ESCPs will, at minimum, avoid any negative impacts that may otherwise arise from their association with unethical behaviours. In the words of one respondent, the utilisation of ethical practices within the supply chain is "always important”.

\section{Acknowledgements}

We are grateful to the reviewers for their critical but constructive comments which helped to improve the overall presentation of the paper.

\section{References}

Amaeshi, K.M., Osuji, O.K. and Nnodim, P. (2008) 'Corporate social responsibility in supply chains of global brands: a boundaryless responsibility? Clarifications, exceptions and implications', Journal of Business Ethics, Vol. 81, No. 1, pp.223-234.

Andersen, M. and Skjoett-Larsen, T. (2009) 'Corporate social responsibility in global supply chains’, Supply Chain Management: An International Journal, Vol. 14, No. 2, pp.75-86.

Arbuthnot, J.J. (1997) 'Identifying ethical problems confronting small retail buyers during the merchandise buying process', Journal of Business Ethics, Vol. 16, No. 7, pp.745-755.

Auroi, C. (2003) 'Improving sustainable chain management through fair trade', Greener Management International, Autumn, No. 43, pp.25-35.

Beamon, B.M. (2005) 'Environmental and sustainability ethics in supply chain management', Science and Engineering Ethics, Vol. 11, No. 2, pp.221-234.

Bendixen, M. and Abratt, R. (2007) 'Corporate identity, ethics and reputation in supplier-buyer relationships', Journal of Business Ethics, Vol. 76, No. 1, pp.69-82.

Bhatnagar, R. and Teo, C. (2009) 'Role of logistics in enhancing competitive advantage: a value chain framework for global supply chains', International Journal of Physical Distribution and Logistics Management, Vol. 39, No. 3, pp.202-222.

Blowfield, M. (1999) 'Ethical trade: a review of developments and issues', Third World Quarterly, Vol. 20, No. 4, pp.753-770.

Blowfield, M. (2004) Ethical Supply Chains in the Cocoa, Coffee and Tea Industries, Greenleaf Publishing, pp.1-10. 
Boulstridge, E. and Carrigan, M. (2000) 'Do consumers really care about corporate responsibility? Highlighting the attitude-behaviour gap’, Journal of Communication Management, Vol. 4, No. 4, pp.355-368.

Bowman, E.H. and Haire, M. (1975) 'Strategic posture toward corporate social responsibility', California Management Review, Vol. 18, No. 2, pp.49-58.

Brennan Jr., J.J., Valtz, J.J., Schallenberger, J.B. and Stanton, V.P. (1961) 'How ethical are businessmen?', Harvard Business Review, Vol. 39, No. 4, pp.6-176.

Carrigan, M. and Pelsmacker, P. (2009) 'Will consumers sustain their values in the global credit crunch?’, International Marketing Review, Vol. 26, No. 6, pp.674-687.

Carroll, A.B. (1991) 'The pyramid of corporate social responsibility: toward the moral management of organizational stakeholders', Business Horizons, Vol. 34, No. 4, pp.39-48.

Carter, C.R. (2000) 'Precursors of unethical behaviour in global supplier management', Journal of Supply Chain Management, Vol. 36, No. 1, pp.45-56.

Carter, C.R. and Jennings, M.M. (2004) 'The role of purchasing in corporate social responsibility: a structural equation analysis', Journal of Business Logistics, Vol. 25, No. 1, pp.145-186.

Carter, J.R., Maltz, A., Maltz, E., Goh, M. and Yan, T. (2010) 'Impact of culture on supplier selection decision making', The International Journal of Logistics Management, Vol. 21, No. 3, pp.353-374.

Ciscel, D.H. and Smith, B.E. (2005) 'The impact of supply chain management on labor standards: the transition to incessant work', Journal of Economic Issues, Vol. 39, No. 2, pp.429-437.

Clarkson, M.B.E. (1995) 'A stakeholder framework for analysing and evaluating corporate social performance’, Academy of Management Review, Vol. 20, No. 1, pp.92-117.

Collinson, C. (2001) The Business Costs of Ethical Supply Chain Management: Kenya Flower Industry Case Study, NRET - Natural Resources and Ethical Trade Programme, NRI Report No. 2607, Project code: V0128, pp.1-40.

Cruz, J.M. and Matsypura, D. (2009) 'Supply chain networks with corporate social responsibility through integrated environmental decision making', International Journal of Production Research, Vol. 47, No. 3, pp.621-648.

Davies, I.A. and Crane, A. (2003) 'Ethical decision making in fair trade companies', Journal of Business Ethics, Vol. 45, Nos. 1/2, pp.79-92.

Debeljak, J. and Krkac, K. (2008) 'Ethics and morality in business practice', Social Responsibility Journal, Vol. 4, Nos. 1/2, p.6.

Desmond, P. (1998) 'A measure of morality', Measuring Business Excellence, Vol. 2, No. 3, pp.4-7.

Donaldson, T. (1996) 'Values in tension: ethics away from home', Harvard Business Review, Vol. 74, No. 5, pp.48-56

Douglas, M.A. and Swartz, S.M. (2009) 'A multi-dimensional construct of commercial motor vehicle operators' attitudes toward safety regulations', The International Journal of Logistics Management, Vol. 20, No. 2, pp.278-293.

Drumwright, M.E. (1994) 'Socially responsible organisational buying: environmental concern as a noneconomic buying criterion', Journal of Marketing, Vol. 58, No. 3, pp.1-19.

Edwards, J.B., McKinnon, A.C. and Cullinane, S.L. (2010) 'Comparative analysis of the carbon footprints of conventional and online retailing: a 'last mile' perspective', International Journal of Physical Distribution and Logistics Management, Vol. 40, Nos. 1/2, pp.103-123.

Ellram, L.M. and Cooper, M.C. (1993) 'Characteristics of supply chain management and the implications for purchasing and logistics strategy', International Journal of Logistics Management, Vol. 4, No. 2, pp.1-10.

Eltantawy, R.A., Fox, G.L. and Giunipero, L. (2009) 'Supply management ethical responsibility: reputation and performance impacts', Supply Chain Management: An International Journal, Vol. 14, No. 2, pp.99-108. 
Emiliani, M.L. (2010) 'Historical lessons in purchasing and supplier relationship management', Journal of Management History, Vol. 16, No. 1, pp.116-136.

Ferrel, O.C., Freedrich, J. and Ferrel, L. (2012) Business Ethics: Ethical Decision Making and Cases, South Western.

Frenkel, S.J. and Scott, D. (2002) 'Compliance, collaboration, and codes of labour practice: the Adidas connection’, California Management Review, Vol. 45, No. 1, pp.29-49.

Giacalone, R.A. and Knouse, S.B. (1996) 'A holistic approach to business ethics', Business and Society Review, Vol. 98, No. 1, pp.46-49.

Gold, S., Seuring, S. and Beske, P. (2010) 'Sustainable supply chain management and interorganizational resources: a literature review', Corporate Social Responsibility and Environmental Management, Vol. 17, No. 4, pp.230-245.

Grace, D. and Cohen, S. (1998) Business Ethics: Australian Problems and Cases, OUP Australia and New Zealand, Melbourne.

Hall, J. and Matos, S. (2010) 'Incorporating impoverished communities in sustainable supply chains', International Journal of Physical Distribution and Logistics Management, Vol. 40, Nos. 1/2, pp.124-147.

Halldorsson, A. and Kovács, G. (2010) 'The sustainable agenda and energy efficiency: logistics solutions and supply chains in times of climate change', International Journal of Physical Distribution and Logistics Management, Vol. 40, Nos. 1/2, pp.5-13.

Hansen, F. and Smith, M. (2006) 'The ethics of business strategy', Handbook of Business Strategy, Vol.7, No. 1, pp.201-206.

Hediger, W. (1999) 'Reconciling 'weak' and 'strong' sustainability', International Journal of Social Economics, Vol. 26, Nos. 7/8/9, pp.1120-1143.

Helms, M.M. and Hutchins, B.A. (1992) 'Poor quality products: is their production unethical?', Management Decision, Vol. 30, No. 5, pp.35-46.

Hughes, A. (2001) 'Global commodity networks, ethical trade and governmentality: organizing business responsibility in the Kenyan cut flower industry', Transactions of the Institute of British Geographers, Vol. 26, No. 4, pp.390-406.

Jones, T.C. and Riley, D.W. (1985) 'Using inventory for competitive advantage through supply chain management', Journal of Physical Distribution and Logistics Management, Vol. 15, No. 5, pp.16-26.

Lange, E.A. and Fenwick, T.J. (2008) 'Moral commitments to community: mapping social responsibility and its ambiguities among small business owners', Social Responsibility Journal, Vol. 4, Nos. 1/2, pp.41-55.

Lindfelt, L. and Tornroos, J. (2006) 'Ethics and value creation in business research: comparing two approaches', European Journal of Marketing, Vol. 40, Nos. 3/4, pp.328-351.

Low, W. and Davenport, E. (2005) 'Has the medium (roast) become the message? The ethics of marketing fair trade in the mainstream', International Marketing Review, Vol. 22, No. 5, pp.494-511.

Lund-Thomsen, P. (2008) 'The global sourcing and codes of conduct debate: five myths and five recommendations', Development and Change, Vol. 39, No. 6, pp.1005-1018.

Maignan, I., Ferrell, O.C. and Hult, G.T.M. (1999) 'Corporate citizenship: cultural antecedents and business benefits', Journal of the Academy of Marketing Sciences, Vol. 27, No. 4, pp.455-469.

Maloni, M.J. and Brown, M.E. (2006) 'Corporate social responsibility in the supply chain: an application in the food industry', Journal of Business Ethics, Vol. 68, No. 1, pp.35-52.

McWilliams, A. and Siegel, D. (2000) 'Corporate social responsibility and financial performance: correlation or misspecification?’, Strategic Management Journal, Vol. 21, No. 5, pp.603-609.

Mollenkopf, D., Stolze, H., Tate, W.L. and Ueltschy, M. (2010) 'Green, lead, and global supply chains', International Journal of Physical Distribution and Logistics Management, Vol. 40, Nos. 1/2, pp.14-41. 
Novack, R.A. and Simco, S.W. (1991) 'The industrial procurement process: a supply chain perspective', Journal of Business Logistics, Vol. 12, No. 1, pp.145-167.

Parker, M. (1998) 'Business ethics and social theory: postmodernizing the ethical', British Journal of Management, Vol. 9 No. 3, pp.27-36.

Peppas, S.C. and Peppas, G.J. (2000) 'Business ethics in the European Union: a study of Greek attitudes’, Management Decision, Vol. 38, No. 6, pp.369-376.

Porter, M. and van der Linde, C. (1995) 'Green and competitive: ending the stalemate', Harvard Business Review, Vol. 73, No. 5, pp.120-134.

Porter, M.E. and Kramer, M.R. (2006) 'Strategy and society: the link between competitive advantage and corporate social responsibility’, Harvard Business Review, Vol. 84, No. 12, pp.78-92.

Pretious, M. and Love, M. (2006) 'Sourcing ethics and the global market: the case of the UK retail clothing sector', International Journal of Retail and Distribution Management, Vol. 34, No. 12, pp.892-903.

Preuss, L. (2001) 'In dirty chains? Purchasing and greener manufacturing', Journal of Business Ethics, Vol. 34, Nos. 3/4, pp.345-359.

Rao, S. and Goldsby, T.J. (2009) 'Supply chain risks: a review and typology', The International Journal of Logistics Management, Vol. 20, No. 1 pp.97-123.

Razzaque, M.A. and Hwee, T.P. (2002) 'Ethics and purchasing dilemma: a Singaporean view', Journal of Business Ethics, Vol. 35, No. 4, pp.307-326.

Reitz, J.H., Wall, J.A. and Love, M.S. (1998) 'Ethics in negotiation: oil and water or good lubrication?’, Business Horizons, Vol. 41, No. 3, pp.5-14.

Roberts, S. (2003) 'Supply chain specific? Understanding the patchy success of ethical sourcing initiatives', Journal of Business Ethics, Vol. 44, Nos. 2/3, pp.159-170.

Seitz, P. (2001) 'Cultural and business ethics', Cross Cultural Management, Vol. 8, No. 1, pp.21-26.

Sen, A. (1997) 'Economics, business principles and moral sentiments', Business Ethics Quarterly, Vol. 7, No. 1, pp.5-15.

Stainer, A. and Stainer, L. (1995) 'Productivity, quality and ethics - a European viewpoint', European Business Review, Vol. 95, No. 6, pp.3-11.

Svensson, G. and Baath, H. (2008) 'Supply chain management ethics: conceptual framework and illustration', Supply Chain Management: An International Journal, Vol. 13, No. 6, pp.398-405.

Svensson, G. and Wood, G. (2003) 'The dynamics of business ethics: a function of time and culture - cases and models', Management Decision, Vol. 41, No. 4, pp.350-361.

Svensson, G. and Wood, G. (2004) 'Proactive versus reactive business ethics performance: a conceptual framework of profile analysis and case illustrations', Corporate Governance, Vol. 4, No. 2, pp.18-33.

Testa, F. and Iraldo, F. (2010) 'Shadows and lights of GSCM (green supply chain management): determinants and effects of these practices based on a multi-national study', Journal of Cleaner Production, Vol. 18, Nos. 10-11, pp.953-962.

Townsend, P.L. and Gebhardt, J.E. (1997) 'Ethics and corporate values - lessons from the US military’, Managing Service Quality, Vol. 7, No. 5, pp.5258-5261.

Trawick, I.F. and Swan, J.E. (1988) 'How salespeople err with purchasers: overstepping the ethical bounds', The Journal of Business and Industrial Marketing, Vol. 3, No. 2, pp.5-11.

Trevino, L.K. and Weaver, G.R. (2003) Managing Ethics in Organizations: A Social Scientific Perspective on Business Ethics, Stanford University Press, California.

Tulder, R., Wijk, J. and Kolk, A. (2009) 'From chain liability to chain responsibility', Journal of Business Ethics, Supplement 2, Vol. 85, Supplement 2, pp.399-412.

Valenzuela, J.L.D. and Villacorta, F.S. (1999) 'The relationships between the companies and their suppliers’, Journal of Business Ethics, Vol. 22, No. 3, pp.273-280. 
Waddock, S.A. and Graves, S.B. (1997) 'The corporate social performance-financial performance link', Strategic Management Journal, Vol. 18, No. 4, pp.303-319.

Weiss, P. (1942) 'Morality and ethics', The Journal of Philosophy, Vol. 39, No. 14, pp.381-385.

Winstanley, D., Clark, J. and Leeson, H. (2002) 'Approached to child labour in the supply chain', Business Ethics: A European Review, Vol. 11, No. 3, pp.210-223.

Wolf, C. and Seuring, S. (2010) 'Environmental impacts as buying criteria for third party logistical services', International Journal of Physical Distribution and Logistics Management, Vol. 40, Nos. 1/2, pp.84-102.

Zadek, S. (1998) 'Balancing performance, ethics, and accountability', Journal of Business Ethics, Vol. 17, No. 13, pp.1422-1441. 